\title{
Application of FTIR Spectroscopy and Chemometrics for the Prediction of Radical Scavenging Activities of Fish oils
}

\author{
Arif Nur Ikhsan', Abdul Rohman²,3*, Anggita Rosiana Putri', Fella Syifa1, Mabrurotul Mustafidah', \\ Ronny Martien ${ }^{4}$
}

1. Postgraduate Student Faculty of Pharmacy Faculty of Pharmacy Universitas Gadjah Mada, Yogyakarta 55281

2. Department of Pharmaceutical Chemistry, Faculty of Pharmacy Universitas Gadjah Mada, Yogyakarta 55281

3. Center of Excellence, Institute for Halal Industry and Systems (PUI-PT IHIS UGM), Universitas Gadjah Mada, Yogyakarta 55281

4. Department of Pharmaceutical Technology, Faculty of Pharmacy Universitas Gadjah Mada, Yogyakarta 55281

\begin{tabular}{|c|c|}
\hline Info Article & ABSTRACT \\
\hline $\begin{array}{l}\text { Submitted: } 23-10-2020 \\
\text { Revised: 07-03-2021 } \\
\text { Accepted: 16-06-2021 } \\
\text { *Corresponding author } \\
\text { Abdul Rohman } \\
\text { Email: } \\
\text { abdulkimfar@ugm.ac.id }\end{array}$ & $\begin{array}{l}\text { Patin (Pangasius micronemus), Gabus (Channa striata) and Bandeng } \\
\text { (Chanos chanos) are the freshwater fishes that are widely cultivated in } \\
\text { Indonesia. Fish oils are believed to have biological activities including } \\
\text { antioxidant activities. The objectives of this study were (1) to determine } \\
\text { radical scavenging activity (RSA) of fish oils using 2,2'-diphenyl-1- } \\
\text { picrylhydrazyl (DPPH) radicals, (2) to classify fish oils from different species } \\
\text { and extraction methods using chemometrics of principal component } \\
\text { analysis (PCA) and cluster analysis (CA) and (3) to predict the antiradical } \\
\text { activities of fish oils from different species and extraction methods using } \\
\text { FTIR spectroscopy combined with principal component regression (PCR) } \\
\text { and partial least square regression (PLSR). The results exhibited that RSA of } \\
\text { Patin fish oil extracted from flesh using maceration technique gave the } \\
\text { highest RSA. PCA and CA were successfully applied for the classification of } \\
\text { fish oils from different species and extraction based on PC1 and PC2 score } \\
\text { plots. Based on dendrogram, the fish oils could be classified into } 4 \text { groups. } \\
\text { The absorbance values of second derivative FTIR spectra at wavenumbers } \\
\text { region of } 1440 \text { - } 1741 \text { cm }-1 \text { provided the highest correlation between actual } \\
\text { values of RSA and FTIR predicted values with coefficient of determination } \\
\text { (R }{ }^{2} \text { ) of } 0.9794 \text {, root mean square error of calibration (RMSEC) of } 0.737 \text { and } \\
\text { root mean square error of prediction (RMSEP) of } 0.927 \text {. From this study, } \\
\text { FTIR spectroscopy combined with chemometrics can be used for } \\
\text { classification of fish oils and for predicting the antioxidant activities of fish } \\
\text { oils from different species and extraction method. } \\
\text { Key words: fish oil, antioxidant activity, FTIR spectroscopy, chemometrics, } \\
\text { DPPH radical scavenging }\end{array}$ \\
\hline
\end{tabular}

\section{INTRODUCTION}

As maritime country, Indonesia has numerous fish species. It is estimated that there are 4000 species of fishes found (Muchlisin and Azizah, 2009). Patin (Pangasius micronemus), Gabus (Channa striata) and Bandeng (Chanos chanos) are the freshwater fishes widely cultivated in Indonesia. Fish oil is a good source of essential fatty acid having antioxidant activities, therefore, fish oils could be considered as functional oils to be supplemented in any types of food and pharmaceutical products (Erdogan et al., 2004; Zzaman et al., 2014; Latip et al., 2014). The recent studies supported that fish oils are essential for improvement the human health caused by the presence of some bioactive compounds in the fish tissue extracted in fish oils (Kuvendziev et al., 2018).

The problems related to oxidative deterioration of lipid-based foods and 
pharmaceuticals is of great economic importance. During oxidation reactions, the mono- and polyunsaturated fatty acids present in edible fats and oils could produce some undesirable odors contributing to off-flavor. The oxidation can also decrease the nutritional values and quality of food and pharmaceutical products, therefore the stable antioxidants are needed (Farvin et al., 2014). Antioxidant can be defined as any substances or materials capable of preventing the oxidation of molecules (Rao, 2016; Archibong et al., 2018). Antioxidants contained in fish oil are influenced by the extraction method used to extract fish oils from different part of fish species. Hydraulic pressing, Soxhlet extraction based on heat extraction, solvent extraction using non-polar solvents (GarcíaMoreno et al., 2014; De Oliveira et al., 2016) and newer extraction methods such as ultrasoundassisted extraction, super critical fluid as well as some green extraction-based on enzymatic methods (Zhang et al., 2021) are reported to extract fish oils (Bonilla-Mendez and HoyosConcha, 2018). Some extraction conditions also affected the extraction efficiency, as a consequence, it is necesarry to select the appropriate extraction method in order to get high antioxidant activities in fish oil (Chaves et al., 2020).

Some methods have been applied for evaluating antioxidant activities of fish oils in vitro including radical scavenging methods using 2,2'diphenyl-1-picrylhydrazyl (DPPH) and 2,2'-azinobis-3-ethylbenzthiazoline-6-sulfonic acid (ABTS), lipid peroxidation inhibition (Akmal and Roh, 2017; Putri et al., 2021), and metal-chelating efficacy (Bag and Chattopadhyay, 2018). These methods are typically required some organic solvents which are hazardous to human health and environment and also involved sample preparation, as a consequence, some instrumental responses are developed for rapid evaluation of antioxidants. One of potential spectroscopic techniques are infrared spectroscopy caused by large information contained in FTIR spectra which are fingerprint in nature (Rohman, 2012).

The use of Fourier transformed-infrared (FTIR) spectroscopy in combination with chemometrics has emerged as powerful technique for the prediction of biological activities (Wu et al., 2012). Among chemometrics techniques, the multivariate calibrations are commonly used to establish the prediction models of biological activities including antioxidants by making the correlation between actual values of antioxidant activities as determined by standard methods and
FTIR predicted values (Lu and Rasco, 2012). The combination of FTIR spectroscopy and multivariate calibration has been successfully applied for prediction of the total antioxidant capacity in four onion varieties and shallot (Lu et al., 2011), red wine (Versari et al., 2010) and chocolate products (Hu et al., 2016). Using literature study, there are no publications regarding the use of FTIR spectroscopy in combination with chemometrics for prediction of antioxidant activities of fish oils from different species. The current study aimed to use FTIR spectra combined with chemometrics to classify fish oils and to predict the antioxidant activities from fish oil.

\section{MATERIAL AND METHODS Materials}

Patin fishes were obtained from several locations in Yogyakarta, East Java Central Java, South Jakarta, and South Kalimantan, Indonesia. Bandeng fishes (milkfish fish) were collected from traditional fish market in Juwana Pati, Central Java, while Gabus fishes were obtained from fish farmer at Yogyakarta. The chemicals of 2,2'-diphenyl-1picrylhydrazyl (DPPH) was purchased from Sigma (Aldrich, USA). The other reagents and solvents used for analysis were of analytical grade and obtained from E. Merck (Darmstadt, Germany).

\section{Sample preparation}

Fish oils were extracted from body parts of flesh, head and offal (Patin), head (Bandeng), as well as offal, head and bone (Gabus). All body parts of fish samples were cut into small pieces and then dried in cabinet dryer about 24 hours, except flesh of Patin which is dried about 2 days at temperature of $50^{\circ} \mathrm{C}$.

\section{Fish oil extractions}

All samples were extracted using press method except Patin flesh which is extracted using maceration, Soxhlet, and Ultrasound Assisted Extraction (UAE) using organic solvents. During maceration, dry and wet fish samples were extracted using $n$-hexane, ethyl acetate, and chloroform for $24 \mathrm{~h}$. Soxhlet extraction was applied on dry and wet fish samples using $n$-hexane and chloroform as extracting solvents for 4 hours. Furthermore, UAE method was carried out using ultrasonic probe UP 200S (Hielscher Ultrasound Technology, Berlin, Germany) with solvent composition of 42\%: 58\% ( $n$-hexane-isopropanol), an amplitude of $41 \%$, a solvent-to-sample ratio of $20: 1$, a cycle of $0.8 \mathrm{~s}^{-1}$, temperature at $59^{\circ} \mathrm{C}$ and 
extraction time of 25 minutes. The solvent was then removed using rotary evaporator at $40^{\circ} \mathrm{C}$. The direct pressing method for fish oil extraction was carried out according to Bako et al. (2017) with slight modification using direct pressing with 100 $\mathrm{kN}$ force for 2 minutes. The oil was separated from sediment by centrifugation at $5000 \mathrm{rpm}$ for 10 minutes. All fish oils obtained were then subjected to antioxidant evaluation using DPPH radical scavenging assay and FTIR spectral measurement.

\section{DPPH radical scavenging activity assay}

DPPH radical scavenging assay was determined according to Akanbi and Barrow (2018) with some modification. A-50 $\mu \mathrm{L}$ of each fish oil samples were added with $1 \mathrm{~mL} 2$,2-diphenyl-1picryl-hydrazyl (DPPH) $0.4 \mathrm{mM}$ and diluted with ethanol to $5.0 \mathrm{~mL}$. The solution mixture was allowed to stand at room temperature in the dark during $30 \mathrm{~min}$. The absorbance of evaluated solutions was measured using spectrophotometer (Hitachi, U-2900, Japan) at 515nm and corrected with blank solutions containing solvent and the studied samples. The absorbance of control solutions containing DPPH• solution was also measured. DPPH radical scavenging activity was calculated as:

$$
\% \text { RSA }=\frac{(\text { Abs control }- \text { Abs sample })}{\text { Abs control }} \times 100 \%
$$

\section{FTIR spectra measurement}

All fish oil samples were analyzed using FTIR spectrophotometer (Thermo Scientific Nicolet iS10, Madison, WI) equipped with software of OMNIC included in FTIR instrument. The spectra were scanned at mid-infrared region of $4000-650 \mathrm{~cm}^{-1}$, scanning number of 32 and the resolution $8 \mathrm{~cm}^{-1}$. All FTIR spectra were corrected against FTIR spectrum of air as background. All samples were measured in three replicates. After each scanning, ATR crystal was cleaned with $n$ hexane twice and acetone once. The spectra were recorded as absorbance values at each data point and used for making the correlation models between antiradical activity and FTIR spectra assisted with multivariate calibrations.

\section{Chemometrics Analysis}

Chemometrics of principal component analysis (PCA) and cluster analysis for classification of fish oils was performed using software of Minitab version 19 (Minitab Inc., USA), while multivariate calibration of partial least square (PLS) and principle component regression
(PCR) used for the prediction of radical scavenging activity was carried out using TQ analyst software (Thermo Fisher Scientific Inc, Madison). Leaveone-out cross-validation was performed to verify PLS and PCR calibration models. The values of root mean square error of calibration (RMSEC), root mean square error of prediction (RMSEP) and coeficient of determination $\left(\mathrm{R}^{2}\right)$ were used as criteria for evaluating the validity of developed models.

\section{RESULT AND DISCUSSION}

The radical scavenging activities (RSA) toward DPPH radicals of fish oils extracted from different parts (flesh, head, offal, head and bone) of fish species (Patin, Bandeng and Gabus) using different extraction techniques (Table I). The highest RSA in Patin fish oil was observed from flesh part extracted using maceration extraction technique accounting of $23.57 \pm 0.14 \%$. Bandeng fish oils extracted from offal part using pressing method had RSA value of $10.71 \pm 0.18 \%$, while Gabus fish oil extracted using pressing method had RSA of $16.26 \pm 0.7 \%$. In general, Patin fish oil had RSA value $>$ Gabus Fish oil > Bandeng fish oil. In Patin, fish oils extracted by chloroform in dried sample using maceration extraction technique had higher antiradical activity than other technique. From this results, it is clear that extraction techniques affected RSA values of fish oils.

In order to classify fish oil samples based on antiradical activities, two unsupervised pattern recognitions, namely principal component analysis (PCA) and cluster analysis (CA) were used. PCA is known as exploratory data analysis which is used for reducing the number of variables if the correlation among variables existed. PCA is an approach to reduce a large of datasets without eliminating the important information in datasets. One of PCA outputs is called principle components (PCs) in which two or more samples having the same PC values are considered as the same samples (Irnawati et al., 2021). As variable, the absorbance values of FTIR spectra of evaluated samples at wavenumber regions of $4500-650 \mathrm{~cm}^{-1}$ were used during PCA. The score plot of PCA from samples based on species and extraction method (Figure 1). The score plot performs the projection of the evaluated samples, as described by the first and second principle component (PC1 and PC2). The closer of the distance to one another, the more similar characteristic of them. 


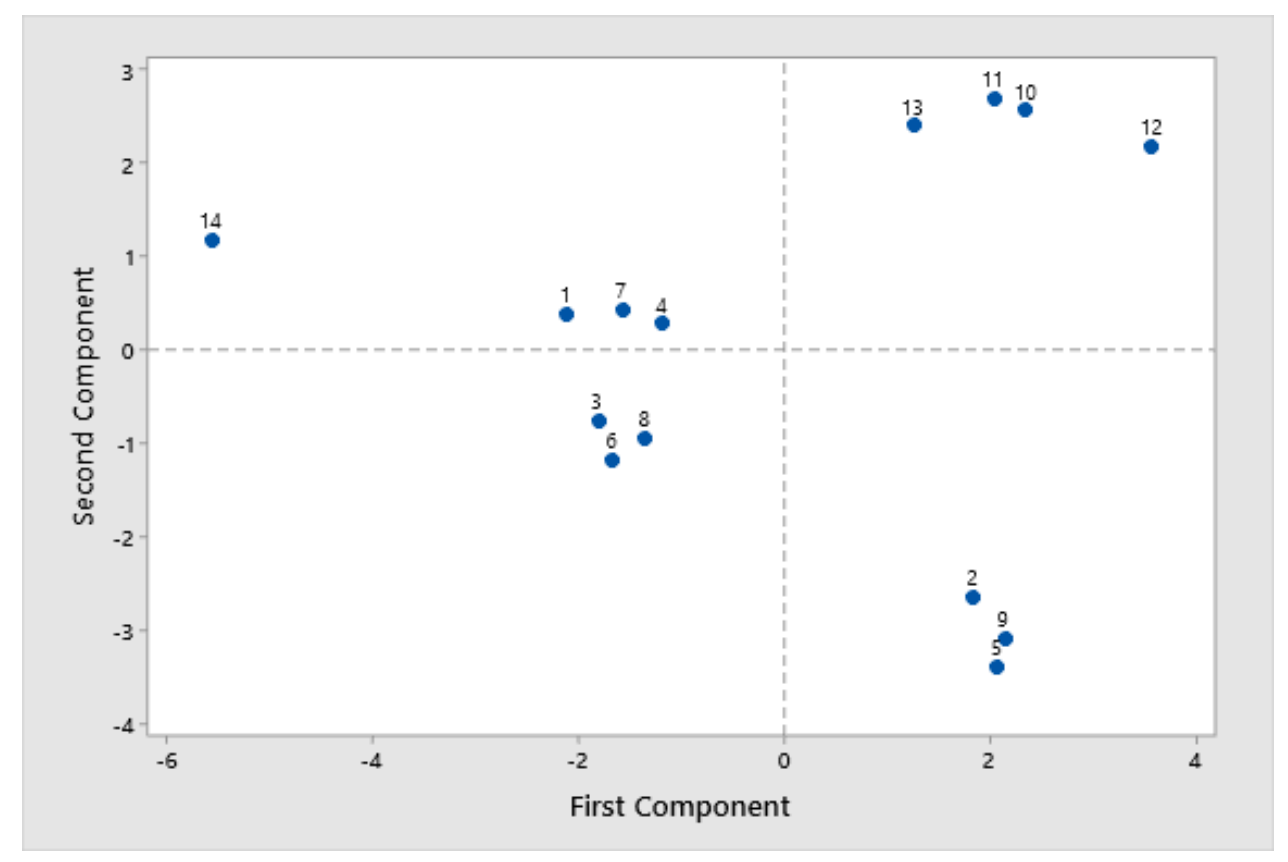

Figure 1. The PCA score plot of fish oil samples from different species and extraction methods. $1=$ PFO by Maceration (n-hexane, wet samples); 2 = PFO by Maceration (ethyl acetate, wet samples); $3=$ PFO by Maceration (chloroform, wet samples); 4 = PFO by Maceration (n-hexane, dried samples); $5=$ PFO by Maceration (ethyl acetate, dried samples); 6 = PFO by Maceration (chloroform, dried samples); $7=$ PFO by Soxhlet (n-hexane, dried samples); 8 = PFO by Soxhlet (chloroform, dried samples); 9 = PFO by UAE (nhexane:isopropanol; dried samples); 10 = PHO by Pressing (dried samples); 11 = POO by Pressing (dried samples); 12 = BHO by Pressing (dried samples); 13 = GHO by Pressing (dried samples); $14=$ GOO byPressing (dried samples). PFO = Patin flesh oil; PHO = Patin Head Oil; BHO = Bandeng Head oil; GHO = Gabus Head Oil; GOO = GabusOffal oil.

Table I. Antioxidant activitiy of fish oil from different species and extraction methods

\begin{tabular}{cccccc}
\hline $\begin{array}{c}\text { Sample } \\
\text { code }\end{array}$ & $\begin{array}{c}\text { Studied } \\
\text { oils }\end{array}$ & $\begin{array}{c}\text { Part of } \\
\text { fish }\end{array}$ & Extraction method & $\begin{array}{c}\text { RSA actual } \\
\text { value }\end{array}$ & $\begin{array}{c}\text { RSA prediction } \\
\text { value }\end{array}$ \\
\hline 1 & PFO & Flesh & Maceration (wet samples, n-hexane) & $19.11 \pm 0.00$ & $20.30 \pm 0.15$ \\
2 & PFO & Flesh & Maceration (wet samples, ethyl acetate) & $13.67 \pm 0.00$ & $13.68 \pm 0.03$ \\
3 & PFO & Flesh & Maceration (wet samples, chloroform) & $21.90 \pm 0.14$ & $21.15 \pm 0.44$ \\
4 & PFO & Flesh & Maceration (dried samples, n-hexane) & $20.50 \pm 0.14$ & $21.65 \pm 0.44$ \\
5 & PFO & Flesh & Maceration (dried samples, ethyl acetate) & $14.04 \pm 0.08$ & $14.27 \pm 0.29$ \\
6 & PFO & Flesh & Maceration (dried samples, chloroform) & $23.57 \pm 0.14$ & $22.43 \pm 0.04$ \\
7 & PFO & Flesh & Soxhlet (dried samples, n-hexane) & $19.20 \pm 0.21$ & $18.83 \pm 0.04$ \\
8 & PFO & Flesh & Soxhlet (dried samples,chloroform) & $19.20 \pm 0.16$ & $20.91 \pm 0.14$ \\
9 & PFO & Flesh & UAE (dried samples ,n-hexane:isopropanol) & $22.78 \pm 0.08$ & $22.22 \pm 0.59$ \\
10 & PHO & Head & Pressing (dried samples) & $10.71 \pm 0.18$ & $11.00 \pm 0.15$ \\
11 & POO & Offal & Pressing (dried samples) & $10.51 \pm 0.30$ & $10.27 \pm 0.17$ \\
12 & BHO & Head & Pressing (dried samples) & $10.71 \pm 0.18$ & $10.80 \pm 0.32$ \\
13 & GHO & Head-bone & Pressing (dried samples) & $16.06 \pm 0.00$ & $16.31 \pm 0.32$ \\
14 & GOO & Offal & Pressing (dried samples) & $16.26 \pm 0.7$ & $15.94 \pm 0.45$ \\
\hline
\end{tabular}

*PFO: Patin Flesh Oils; PHO= Patin Head Oils; POO =Pation Offal Oils; BHO: Bandeng Head Oils; GHO: Gabus Head Oils; GOO = Gabus Offal Oils; and RSA = Radical Scavenging Activity. 


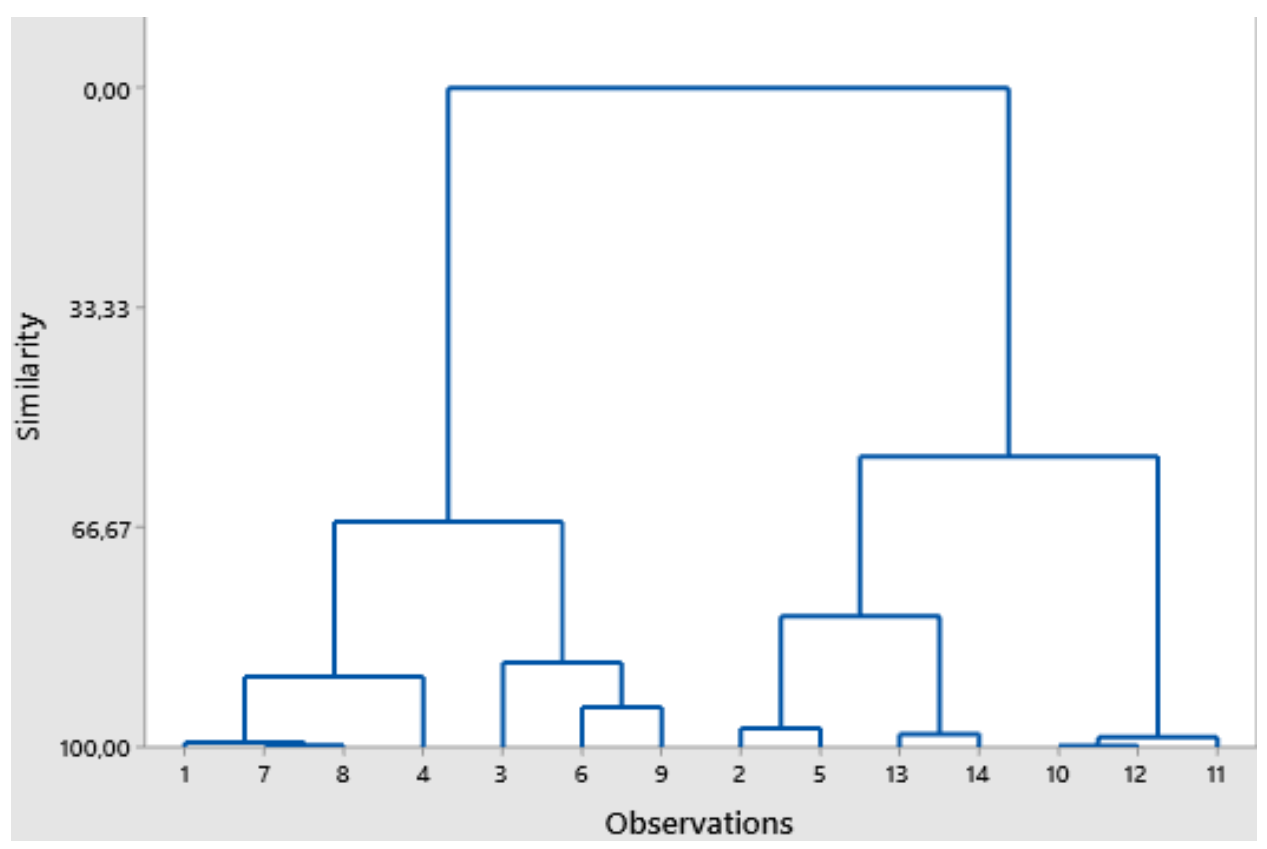

Figure 2. The dendrogram of fish oil samples from different species and extraction methods. $1=$ PFO by Maceration (n-hexane, wet samples); 2 = PFO by Maceration-(ethyl acetate, wet samples); 3 = PFO by Maceration (chloroform, wet samples); 4 = PFO by Maceration (n-hexane, dried samples); 5 = PFO by Maceration (ethyl acetate, dried samples); 6 = PFO by Maceration (chloroform, dried samples); 7 = PFO by Soxhlet (n-hexane, dried samples); 8 = PFO by Soxhlet (chloroform, dried samples); 9 = PFO by UAE (n-hexane:isopropanol, dried samples); 10 = PFO by Pressing-(dried samples); 11 = POO by Pressing (dried samples); 12 = BHO by Pressing(dried samples); 13 = GHO by Pressing (dried samples); 14 = GOO by Pressing (dried samples). PFO = Patin flesh oil; BHO = Bandeng head oil; GHO = Gabus head oil; GOO = Gabus offal oil.

PFO extracted by maceration using ethyl acetate (wet and dried samples) and PFO extracted by UAE having similar characteristic since they are close to each other in score plot. Based on score plot values, PC1-PC5 could extract more than $95 \%$ of information from original data.

Cluster analysis (CA) is a process of identifying the grouping of evaluated samples based on the similarity measure which is represented as a dendogram (Omran et al., 2007). CA is based on Euclidian distance (Ed) in which two or more samples with Ed equal to zero can be considered as the same samples (Miller and Miller, 2005). In this study, clustering algorithm can be used as a simple tool for categorizing fish oil samples based on antiradical scavenging activity from different species and extraction methods, and the dendogram obtained was depicted (Figure 2). The firstly joined samples are Patin head oil (PHO) extracted by pressing and Bandeng head oil (BHO) extracted by pressing followed by Patin flesh oil (PFO) Soxhlet ( $n$-hexane) and PFO Soxhlet (chloroform) and so on until all samples are grouped into one group. Cluster analysis suggests that fish oil samples based on variable of antiradical activities could be divided into four groups. Group 1 consisted of PFO by maceration, PFO by soxhlet (n-hexane), PFO by soxhet (chloroform), and PFO by maceration (chloroform, dried samples). Group 2 consisted PFO by maceration (chloroform, wet samples), PFO by maceration (chloroform, dried samples), and PFO by UAE. Group 3 consisted PFO by maceration (ethyl acetate, wet samples), PFO by maceration (ethyl acetate, dried samples), GHO by pressing, and Gabus Offal oil (GOO) extracted by pressing method. Group 4 consisted Patin head oil (PHO) extracted by pressing, Bandeng head oil (BHO) by pressing, and Patin offal oil (POO) by extracted by pressing ethod.

In order to predict the radical scavenging activity (RSA) of fish oil samples, two multivariate calibrations namely principle component regression (PCR) and partial least square (PLS) were applied. The variation in FTIR spectra of fish oil samples can be exploited to build the calibration model for the prediction of RSA. 
Table I. The optimization of multivariate calibrations of principle component regression (PCR) and partial least square (PLS) for prediction of radical scavenging activity of fish oil samples from different species and extraction method

\begin{tabular}{|c|c|c|c|c|c|c|}
\hline \multirow{2}{*}{$\begin{array}{l}\text { Multivariate } \\
\text { Calibration }\end{array}$} & \multirow{2}{*}{ Wavenumber $\left(\mathrm{cm}^{-1}\right)$} & \multirow{2}{*}{ Spectra } & \multicolumn{2}{|c|}{ Calibration } & \multicolumn{2}{|c|}{ Prediction } \\
\hline & & & RMSEC & $\mathbf{R}^{2}$ & RMSEP & $\mathbf{R}^{2}$ \\
\hline \multirow{15}{*}{ PLS } & \multirow{3}{*}{$650-818$} & Normal & 0.600 & 0.9903 & 3.70 & 0.6248 \\
\hline & & $1^{\text {st }}$ derivative & 0.641 & 0.9890 & 3.70 & 0.6193 \\
\hline & & $2^{\text {nd }}$ derivative & 0.590 & 0.9906 & 4.19 & 0.6122 \\
\hline & \multirow{3}{*}{$1440-1741$} & Normal & 2.12 & 0.8715 & 2.11 & 0.8731 \\
\hline & & $1^{\text {st }}$ derivative & 3.03 & 0.7134 & 3.01 & 0.7210 \\
\hline & & $2^{\text {nd }}$ derivative & 3.13 & 0.6900 & 3.13 & 0.6913 \\
\hline & \multirow{3}{*}{$1359-1455$} & Normal & 2.44 & 0.8256 & 2.43 & 0.8394 \\
\hline & & $1^{\text {st }}$ derivative & 2.24 & 0.8562 & 2.33 & 0.8441 \\
\hline & & $2^{\text {nd }}$ derivative & 3.77 & 0.4916 & 3.82 & 0.4721 \\
\hline & \multirow{3}{*}{$1600-1700$} & Normal & 1.37 & 0.9489 & 1.93 & 0.9000 \\
\hline & & $1^{\text {st }}$ derivative & 2.25 & 0.8546 & 2.24 & 0.8560 \\
\hline & & $2^{\text {nd }}$ derivative & 3.68 & 0.5258 & 3.69 & 0.5223 \\
\hline & \multirow{3}{*}{$1040-1122$} & Normal & 1.18 & 0.9620 & 1.31 & 0.9539 \\
\hline & & $1^{\text {st }}$ derivative & 3.06 & 0.7080 & 3.10 & 0.6976 \\
\hline & & $2^{\text {nd }}$ derivative & 2.62 & 0.7964 & 2.57 & 0.8066 \\
\hline \multirow{15}{*}{ PCR } & \multirow{3}{*}{$650-818$} & Normal & 1.06 & 0.9692 & 3.42 & 0.6808 \\
\hline & & $1^{\text {st }}$ derivative & 1.86 & 0.9033 & 3.07 & 0.7312 \\
\hline & & $2^{\text {nd }}$ derivative & 0.737 & 0.9854 & 3.77 & 0.6316 \\
\hline & \multirow{3}{*}{$1440-1741$} & Normal & 0.856 & 0.9802 & 0.902 & 0.9794 \\
\hline & & $1^{\text {st }}$ derivative & 0.787 & 0.9833 & 0.966 & 0.9750 \\
\hline & & $2^{\text {nd }}$ derivative & 0.737 & 0.9854 & 0.927 & 0.9781 \\
\hline & \multirow{3}{*}{$1359-1455$} & Normal & 1.78 & 0.9119 & 1.76 & 0.9157 \\
\hline & & $1^{\text {st }}$ derivative & 0.868 & 0.9797 & 0.882 & 0.9835 \\
\hline & & $2^{\text {nd }}$ derivative & 0.881 & 0.9791 & 1.27 & 0.9584 \\
\hline & \multirow{3}{*}{$1600-1700$} & Normal & 1.45 & 0.9422 & 1.97 & 0.9069 \\
\hline & & $1^{\text {st }}$ derivative & 1.32 & 0.9526 & 1.00 & 0.9037 \\
\hline & & $2^{\text {nd }}$ derivative & 1.44 & 0.9426 & 2.32 & 0.8777 \\
\hline & \multirow{3}{*}{$1040-1122$} & Normal & 1.28 & 0.9555 & 1.32 & 0.9535 \\
\hline & & $1^{\text {st }}$ derivative & 1.32 & 0.9525 & 1.45 & 0.9438 \\
\hline & & $2^{\text {nd }}$ derivative & 1.65 & 0.9244 & 1.68 & 0.9269 \\
\hline
\end{tabular}

The selection condition was marked with italicized bold.

The wavenumber regions and FTIR spectral treatment were optimized to obtain the best prediction model in terms of providing highest $\mathrm{R}^{2}$ values and lowest RMSEC and RMSEP values. Figure 3 showed attenuated total reflectance-FTIR spectra along with functional groups present in studied fish oils responsible for the absorption of infrared radiation. Some optimizations of wavenumber regions and spectral treatment along with multivariate calibration techniques were carried out, and the statistical performance (Table II). The optimal prediction condition was obtained using second derivative FTIR spectra at wavenumbers region $1440-1741 \mathrm{~cm}^{-1}$ assisted by PCR with $\mathrm{R}^{2}$-calibration value of $0.9854, \mathrm{R}^{2}$ prediction value of 0.9781 , RMSEC value of 0.737 and RMSEP value of 0.927 . Figure 4 revealed the correlation between actual value of RSA ( $\mathrm{x}$-axis) and FTIR predicted value (y-axis) assisted with PCR. High $\mathrm{R}^{2}$ value and low errors (RMSEC and RMSEP) indicated that FTIR spectroscopy in combination with PCR could be an alternative method for predicting RSA accurately and precisely. 


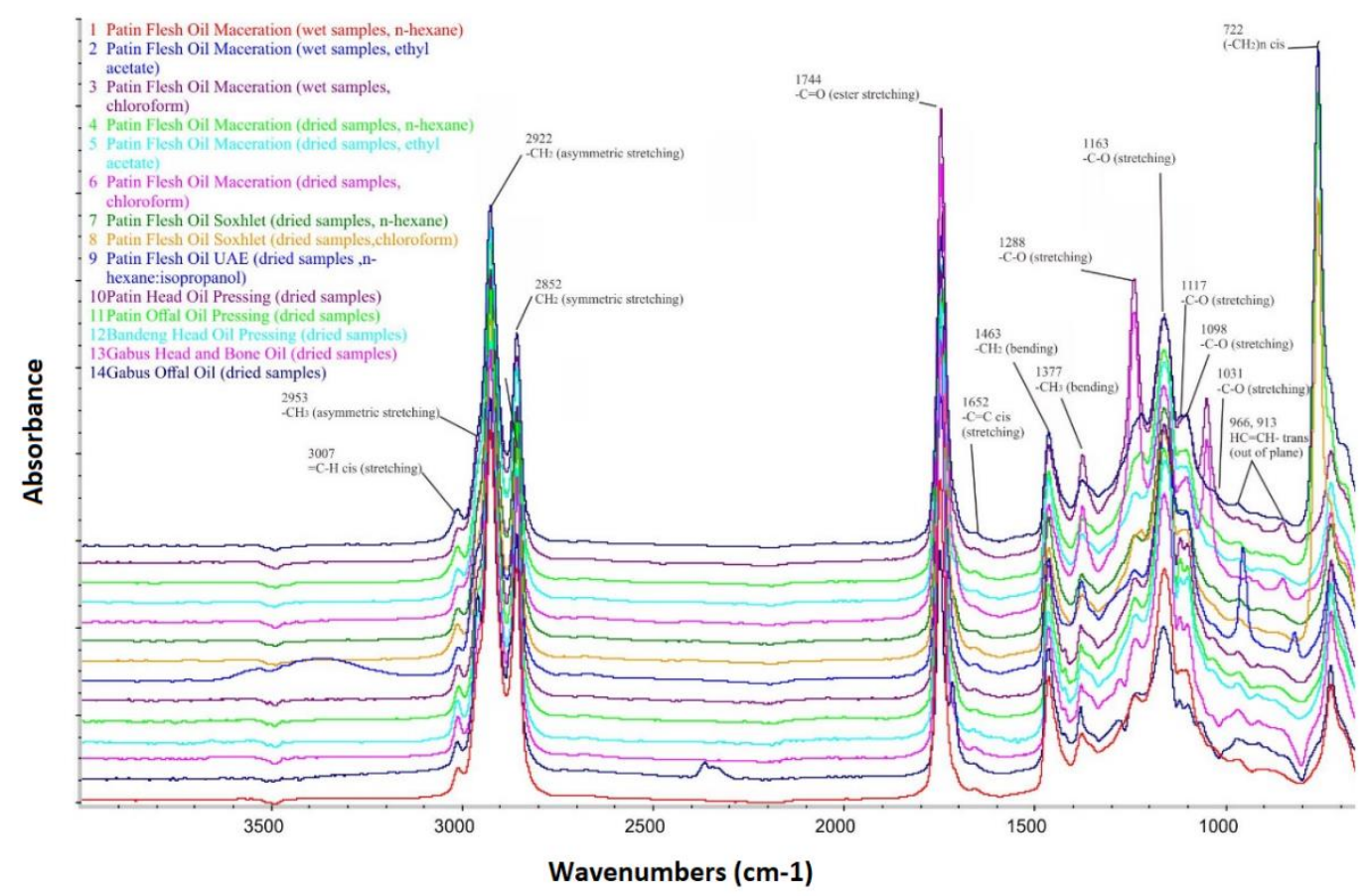

Figure 3. Attenuated total reflectance-FTIR spectra of fish oil samples from different species and extraction methods, scanned at mid infrared region (4000-650 $\left.\mathrm{cm}^{-1}\right)$.

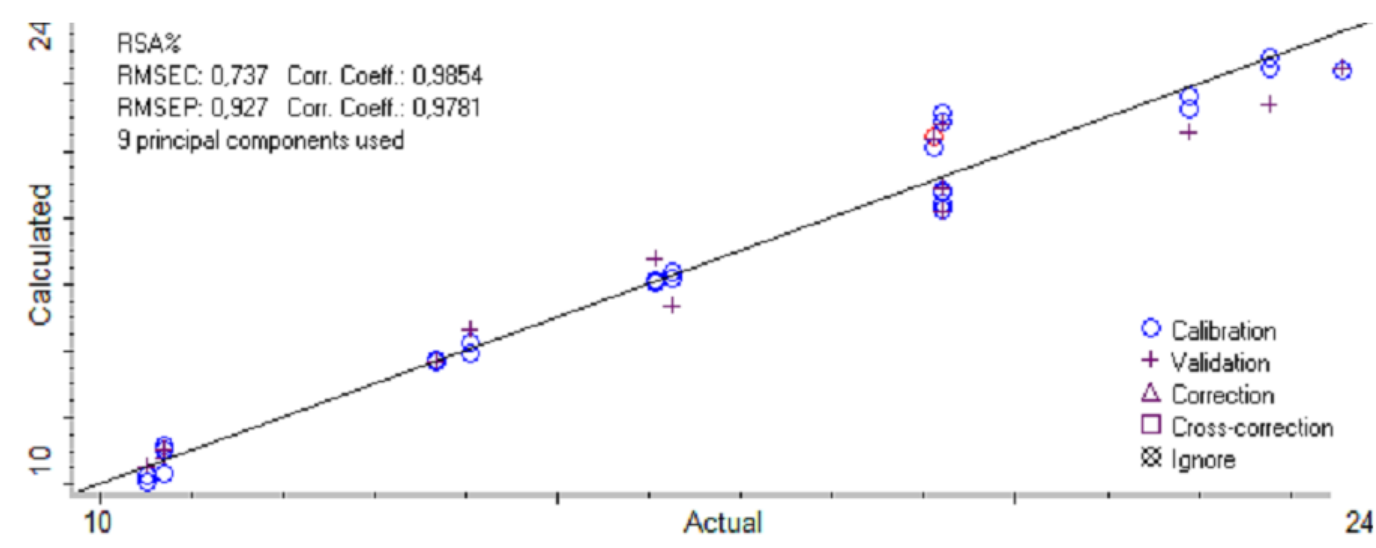

Figure 4. PLS calibration model for correlation between actual and predicted value of radical scavenging activities of fish oil samples. The $\mathrm{x}$-axis showed the actual radical scavenging activity, the $y$-axis showed the calculated radical scavenging activity based on FTIR spectra using the optimum condition. 


\section{CONCLUSION}

FTIR spectroscopy in combination with PCA and CA has been successfully applied for classification of fish oils originating from fish species of Patin, Gabus and Bandeng. Moreover, FTIR spectroscopy at wavenumber $1440-1741 \mathrm{~cm}^{-1}$ combined with PCR could be an alternative method for predicting RSA with high accuracy and low error based on high $\mathrm{R}^{2}$ and low RMSEC and RMSEP values.

\section{ACKNOWLEDGEMENT}

The authors thank to the Ministry of Research, Technology and Higher Education, Republic Indonesia.

\section{REFERENCES}

Akmal NLHBI, Roy A., 2017. Free radical scavenging activity of fish oil - an in-vitro study. Int. J. Pharm. Sci. Res., 8(9): 3872-75.

Akanbi TO, Barrow CJ., 2018. Lipase-produced hydroxy tyrosyl eicosapentaenoate is an excellent antioxidant for the stabilization of omega-3 bulk oils, emulsions and microcapsules. Molecules, 23(2): 275. doi: $10.3390 /$ molecules 23020275

Archibong AE, Rideout ML, Harris KJ, Ramesh A., 2018. Oxidative stress in reproductive toxicology. Curr. Opinion Toxicol., 7: 95-101.

Bag A, Chattopadhyay RR., 2018. Evaluation of antioxidant potential of essential oils of some commonly used Indian spices in in vitro models and in food supplements enriched with omega- 6 and omega-3 fatty acids. Environ. Sci. Pollut. Res. Int., 25(1): 388-398.

Bako T, Umogbai VI, Awulu JO., 2017. Criteria for the extraction of fish oil. Agric. Eng. Int., 19(3): 120-132.

Bonilla-Mendez JR, Hoyos-Concha JL., 2018. Methods of extraction, refining and concentration of fish oil as a source of omega-3 fatty acids. Corpoica Cienc. y Tecnol. Agropecu, 19(3): 645-668.

Chaves N, Santiago A, Alías JC., 2020. Quantification of the antioxidant activity of plant extracts: Analysis of sensitivity and hierarchization based on the method used. Antioxidants, 9(1): 76; doi:10.3390/antiox9010076

Che Man YB, Rohman A, Mansor TST., 2011. Differentiation of lard from other edible fats and oils by means of Fourier transform infrared spectroscopy and chemometrics. J. Am. Oil Chem. Soc., 88(2): 187-192.

De Oliveira DA, Minozzo MG, Licodiedoff S, Waszczynskyj N., 2016. Physicochemical and sensory characterization of refined and deodorized tuna (Thunnus albacares) byproduct oil obtained by enzymatic hydrolysis. Food Chem., 207: 187-194.

Erdogan H, Fadillioglu E, Ozgocmen S, Sogut $S$, Ozyurt B, Akyol O, Ardicoglu O., 2004. Effect of fish oil supplementation on plasma oxidant/antioxidant status in rats. Prostaglandins Leukot. Essen. Fatty Acids, 71(3): 149-152.

Farvin KHS, Andersen LL, Nielsen HH, Jacobsen C, Jakobsen G, Johansson I, Jessen F., 2014. Antioxidant activity of Cod (Gadus morhua) protein hydrolysates: In vitro assays and evaluation in $5 \%$ fish oil-in-water emulsion. Food Chem., 149: 326-334.

García-Moreno PJ, Morales-Medina R, P'erez-G' alvez R, Bandarra NM, Guadix A, Guadix EM., 2014. Optimisation of oil extraction from sardine (Sardina pilchardus) by hydraulic pressing. Int J Food Sci Technol., 49(10): 2167-2175.

Hu Y, Pan ZJ, Liao W, Li J, Gruget P, Kitts DD, Lu X., 2016. Determination of antioxidant capacity and phenolic content of chocolate by attenuated total reflectance-Fourier transformed-infrared spectroscopy. Food Chem., 202: 254-261.

Ilza M, Sukmiwati M., 2020. The Use of "jambal" Fish (Pangasius hypophtalmus) and Grouper (Cromileptes sp) Oils for Infant Biscuit Formulation. IOP Conf. Series: Earth Environm. Sci., 430(1).

Irnawati, Riswanto FDO, Riyanto S, Martono S, Rohman A., 2021. Tthe use of software of factoextra and FactoMineR and application of principal component analysis for authentication of fats and oils). Indonesian. J. Chemom. Pharm. Anal. 1: 1-10.

Kuvendziev S, Lisichkov K, Zeković Z, Marinkovski M, Musliu ZH., 2018. Supercritical fluid extraction of fish oil from common carp (Cyprinus carpio L.) tissues. J. Supercritic. Fluids, 133: 528-534.

Latip LD, Zzaman W, Yang TA., 2014. Application of Response Surface Methodology to Optimize the Extraction of Asian Catfish (Clarias Batrachus) Oil Using Superheated Steam Treatment. Food Sci. Technol., 2(6): 69-76. 
Lu X, Rasco BA., 2012. Determination of Antioxidant Content and Antioxidant Activity in Foods using Infrared Spectroscopy and Chemometrics: A Review. Crit. Rev. Food Sci. Nutr., 52(10): 853-875.

Lu X, Wang J, Al-Qadiri HM, Ross CF, Powers JR, Tang J, Rasco BA., 2011. Determination of total phenolic content and antioxidant capacity of onion (Allium cepa) and shallot (Allium oschaninii) using infrared spectroscopy. Food Chem., 129(2): 637-644.

Miller JC, Miller JN., 2005. Chemometrics for Analytical (Fifth edition). Harlow: Pearson Education.

Muchlisin ZA, Azizah MNS., 2009. Diversity and distribution of freshwater fishes in aceh water, Northern-Sumatra, Indonesia. Int. J. Zool. Res., 6(2): 166-183.

Omran MGH, Engelbrecht AP, Salman A., 2007. An overview of clustering methods. Intell. Data Anal., 11(6): 583-605.

Putri AR, Rohman A, Riyanto S, Setyaningsih W., 2021. Classification and prediction of patin fish oil's antioxidant activities from different origins using FTIR spectroscopy and chemometrics. Int. J. Pharm. Res., 13(1): 990-998.

Rao VR., 2016. Antioxidant Agents. In Advances in Structure and Activity Relationship of Coumarin Derivatives, Amsterdam: Elsevier.
Rohman A., 2012. Application of FTIR spectroscopy for quality control in pharmaceutical products: a review. Indonesian J. Pharm., 23(1): 1 -8.

Versari A, Parpinello GP, Scazzina F, Rio D., 2010. Prediction of total antioxidant capacity of red wine by Fourier transform infrared spectroscopy. Food Control, 21(5): 786-789.

Windarsih A, Irnawati, Rohman A., 2020. Application of FTIR - ATR spectroscopy and chemometrics for the detection and quantification of lard oil in bovine milk fat. Food Res., 4(5): 1732-1738.

Wu D, Chen J, Lu B, Xiong L, He Y, Zhang Y., 2012. Application of near infrared spectroscopy for the rapid determination of antioxidant activity of bamboo leaf extract. Food Chem., 135(4): 2147-2156.

Zhang Y, Sun X, Liu S, Wei S, Xia Q, Ji H, Deng C, Hao J., 2021. Extraction of fish oil from fish heads using ultra-high pressure pre-treatment prior to enzymatic hydrolysis. Innov. Food Sci. Emerg. Technol., 70: 102670.

Zzaman W, Suseno S, Nadiah W, Tajul A., 2014. Fatty Acid Profile and Antioxidant Capacity of Muscle and by Product Oil from Selected Fresh Water Fish. Food Sci. Technol., 2(3): 41-46. 